\title{
Determination of pressure in the extradendritic liquid area during solidification
}

\author{
P. Svidró ${ }^{1}$ (D) A. Diószegi ${ }^{1}$ (D) P. G. Jönsson ${ }^{2}$ (D) D. M. Stefanescu ${ }^{3}$ (D)
}

Received: 23 August 2017 / Accepted: 16 February 2018/Published online: 7 March 2018

(c) The Author(s) 2018. This article is an open access publication

\begin{abstract}
Complex-shaped lamellar graphite iron castings are susceptible to casting defects related to the volume change during solidification. The formations of these recurring defects are caused by the flow of the liquid in the intradendritic area, between the austenite dendrite arms, and in the extradendritic area between the austenite grains. The conditions for the liquid flow, in turn, are determined by the solidification behavior. The present study suggests a new measurement method and a novel calculation algorithm to determine the pressure of the extradendritic liquid during solidification. The method involves a spherical sample suspended in a measurement device, where the temperature and the volume changes are measured during solidification. The calculation algorithm is based on the numerical interpretation of the ClausiusClapeyron equation where the temperature variation, the volume change and the released latent heat are processed to determine the local pressure of the extradendritic liquid area during solidification.
\end{abstract}

Keywords Volume change measurement · Fourier thermal analysis - Clausius-Clapeyron equation · Extradendritic liquid pressure $\cdot$ Lamellar graphite iron

\section{Introduction}

The solidification of a hypoeutectic lamellar graphite iron under industrial conditions starts with the formation of columnar grains nucleated on the wall of the mold. These grains interact with the mold wall to create a zone, which

P. Svidró

peter.svidro@ju.se

A. Diószegi

Attila.dioszegi@ju.se

P. G. Jönsson

parj@kth.se

D. M. Stefanescu

stefanescu.1@osu.edu

1 Department of Materials and Manufacturing - Foundry Technology, School of Engineering, Jönköping University, Gjuterigatan 5, 55111 Jönköping, Sweden

2 Department of Material Science and Technology, School of Industrial Engineering and Management, Royal Institute of Technology, Brinellvägen 23, 10044 Stockholm, Sweden

3 Department of Materials Sciences and Engineering, The Ohio State University, Columbus, OH, USA represents a container-like macro-volume of the casting. Inside this container equiaxed grains are formed, based on heterogeneous nucleation. The grain growth continues until the columnar and equiaxed grains collide and form a coherent skeleton of a metallic matrix [1]. Depending on the dendrite morphology at the collision, a significant fraction of liquid phase still exists between the dendrite arms (intradendritic liquid) and in between the austenite grains (extradendritic liquid). Thereafter, the solidification continues with a dynamic coarsening process involving a combination of the coarsening and an increase in the solid fraction of austenite [2]. The decreasing fraction of liquid which is enriched by the segregated carbon forms a graphite austenite eutectic in the intradendritic space. Finally, the extradendritic phase solidifies to complete the liquidsolid transformation process.

Recent studies on lamellar graphite iron complexshaped parts were performed to study the kinetic of the casting defect formations. Two frequently occurring defects were studied, namely the shrinkage porosity (SP) and the metal expansion penetration (MEP) [1] (see Fig. 1). In the case of an SP formation, the gaseous external environment is pushed into the extradendritic space over 


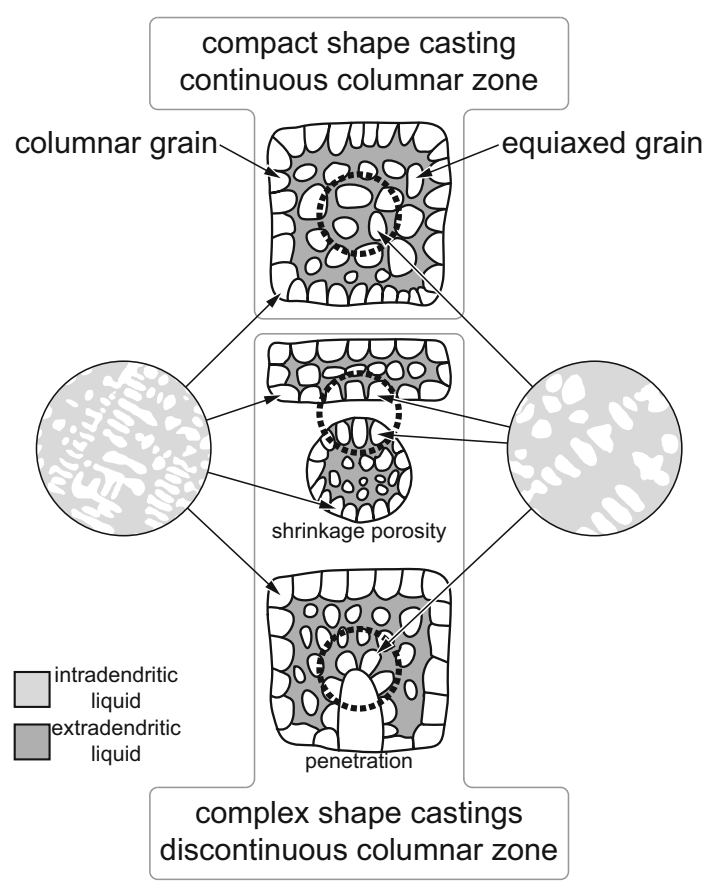

Fig. 1 Schematic diagram of the shrinkage porosity and metal expansion penetration formation mechanisms in lamellar graphite iron with respect to the casting geometry. Dashed lines indicate the location of the thermal hot spot

the metal-mold surface where the columnar zone has not been formed. MEP defects form as the extradendritic liquid is squeezed over the metal-mold interface, either by deforming the mold surface or by penetrating between the sand grains. Upon the solidification of compact geometries, where the columnar zone was coherent, neither SP or MEP defects were observed [3].

An important piece of information to understand the formation of SP and MEP defects is the conditions when the formation is driven by the mass transport over the casting surface in different directions. In the case of an SP defect formation, a pressure reduction that can be expressed as an expansion pressure on the extradendritic liquid is believed to be necessary to promote a gas intrusion. However, in the case of a MEP defect, the formation of a pressure increment that can be expressed as a compressive pressure on the extradendritic liquid is believed to be the driving force for the metal extrusion. It should be stressed that no methods for direct measurements of the expansion and compressive pressures of liquid metals have been reported in the open literature, according to the authors' knowledge. However, analytical equations to determine these properties are available [4-8].

The scope of the present paper is to present a novel measurement and calculation method to predict the pressure of the liquid phase during solidification of lamellar graphite iron.

\section{Experimental}

Volume change measurement during the solidification of cast alloys is reported by only a few authors [9-13]. Some of the authors of the present paper have published a review on the problems of volume change measurement [14]. Based on that study, an idea for a new experimental arrangement was developed. This arrangement included a spherical sample, which was designed for the experimental purposes. The components of the sampler are presented in Fig. 2.

1. Spherical metal mold made of steel with a wall thickness of $0.5 \mathrm{~mm}$. The diameter of the top opening is $12 \mathrm{~mm}$

2. Lid made of the same material and the same wall thickness as the spherical metal mold. The diameter of the lid is $18 \mathrm{~mm}$, and it is welded to a steel tube.

3. Steel tube made of the same material as the spherical metal mold, which is closed at one end.

The arrangement of the measuring units is presented in Fig. 3.

1. Push rod made of engineering grade full-fired $99.8 \%$ polycrystalline alumina. The three push rods transfer the displacement of the surface to the linear variable differential transformer (LVDT). The LVDT has a measuring range of $\pm 3 \mathrm{~mm}$, a sensitivity of $85.20 \mathrm{mV} / \mathrm{V} \mathrm{mm}$, and a linearity of $\pm 0.05 \%$ for a full-scale output.

2. Representation of the field-of-view of the infrared (IR) thermometer. The IR unit is equipped with a two-color spectral sensor and has a measuring range of $500-1400{ }^{\circ} \mathrm{C}$.

The spherical metal mold is filled up through the circular opening when the sample collector is immersed in the

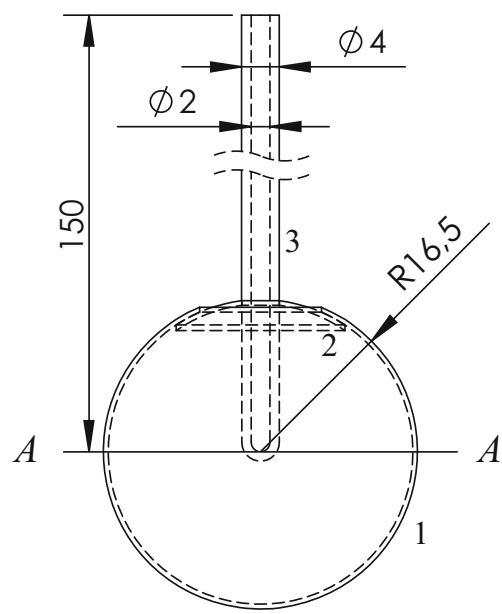

Fig. 2 Components of the spherical sampler 


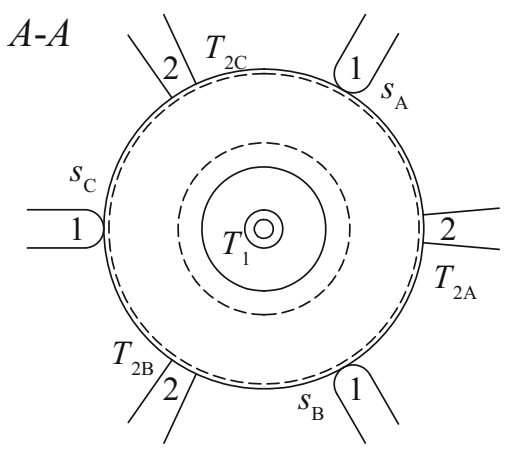

Fig. 3 Arrangement of the sensors and accessories

liquid metal. The spherical shell moves independently from the adherent lid. The filled sample is then lifted to the measuring position while hanging on the lid. The sensitive end of the thermocouple is situated in the geometric center of the sphere $T_{1}$. The thermocouple is $N$ type as described in the ASTM E608/E608M standard. The LVDT and the IR sensors are distributed equally around the sample on a plane that crosses the geometrical center of the sphere. Moreover, each sensor is oriented perpendicularly to the surface of the sphere. The $T_{2 \mathrm{~A}}, T_{2 \mathrm{~B}}$ and $T_{2 \mathrm{C}}$ represent the spots for the temperature measurements. The $s_{\mathrm{A}}, s_{\mathrm{B}}$ and $s_{\mathrm{C}}$ represent the spots for the displacement measurements on the surface of the sample. The use of a steel tube allows for the reuse of the thermocouple, due to the protection from erosion from the melt. The selection of alumina rods serves as to protect the LVDTs. The accuracy of the displacement measurement is maintained as the linear thermal expansion coefficient of the alumina is $6.3\left[10^{-6} \mathrm{gr} \mathrm{C}^{-1}\right]$.

The investigated alloy was taken from a 4-ton induction furnace by using a hand-held ceramic fiber cup, at a melt temperature of $1450{ }^{\circ} \mathrm{C}$. The chemical composition of the alloy was determined by using an optical emission spectrometer, and the result is shown in Table 1.

During an experiment, the spherical sample was submerged into the cup holding the melt for $2.5 \mathrm{~s}$. The measurement started as the measurement device touched the surface of the spherical sample with the push rods. The temperature values from the thermocouple, the IR values, and the displacement values from the LVDTs were registered with a sampling frequency of ten samples per second.

Table 1 Chemical composition (mass $\%$ ) and carbon equivalent $(\mathrm{CE}=\% C+\% \mathrm{Si} / 3+\% P / 3)$ values of the alloy

\begin{tabular}{lllllllll}
\hline Element & $C$ & $\mathrm{Si}$ & $\mathrm{Mn}$ & $P$ & $S$ & $\mathrm{Cr}$ & $\mathrm{Cu}$ & $\mathrm{CE}$ \\
\hline mass\% & 3.2 & 1.88 & 0.61 & 0.03 & 0.03 & 0.15 & 0.28 & 3.85 \\
\hline
\end{tabular}

\section{Calculation algorithm}

Solidification is usually described as a phase transformation under the assumption that the solid/liquid interface is under local thermodynamic equilibrium. The driving force of the solidification is the change of the free energy, which is driven by the temperature undercooling below the equilibrium temperature. The solid/liquid curvature, the temperature, the chemical composition and the pressure variation are considered as influencing parameters on the undercooling [15]. The change in free energy of the liquid and solid with small changes in temperature $\Delta T_{\mathrm{p}}$ can be expressed using Eq. (1), which is the Clausius-Clapeyron equation:

$\Delta T_{\mathrm{p}}=\frac{\Delta P \Delta v}{\Delta s}$

where $\Delta P$ is the pressure variation, $\Delta v$ is the specific volume change, and $\Delta s$ is the specific entropy change of the solidification. The entropy change as it was defined by Clausius can be expressed as a function of the heat release at solidification $\mathrm{L}$ and the absolute temperature of the system $\mathrm{T}$.

$\Delta s=\frac{L}{T}$

By including Eq. (2) into (1) and by considering differential notation for the pressure and temperature term, the following relationship can be obtained:

$\frac{\mathrm{d} P}{\mathrm{~d} T}=\frac{L}{T \Delta v}$

Equation (3) equates the slope of the tangent to the coexistence curve (between two phases), $\frac{\mathrm{d} P}{\mathrm{~d} T}$ at any given point on the curve, to the function $\frac{L}{T \Delta v}$. As such, it is valid for condensed phases, and consequently for the liquid/solid transformation.

Since Eq. (3) was derived by assuming a constant pressure and temperature, it is possible to transform the partial derivatives into total derivatives.

Considering the solidification interval of the metallic alloy (e.g., hypoeutectic cast iron), the solidification interval can be divided in solidification increments delimited by time intervals. Consequently, the pressure change for a small solidification increment can be calculated, by considering the release of latent heat and the specific volume change strictly related to the considered solidification increment. For this scope, the latent heat of solidification $\mathrm{L}$ $\left(\mathrm{J} \mathrm{kg}^{-1}\right)$, which represents the released latent heat within the whole solidification interval is replaced with the heat quantity $Q_{\mathrm{s}}\left(\mathrm{J} \mathrm{kg}^{-1}\right)$, which represents the released latent heat only during the considered solidification increment. 
It is possible to replace $L$ with $Q_{\mathrm{s}}$ in Eq. (3) and to carry out an integration. The left-hand side term is integrated from $P_{1}$ to $P_{2}$, which are the pressure in the beginning and at the end of the solidification increment. Furthermore, the right-hand side term is integrated from $T_{1 \text {,start }}$ to $T_{1 \text {,end }}$, which are the central temperature of the sample in the beginning and at the end of the solidification increment:

$$
\int_{P_{1}}^{P_{2}} \mathrm{~d} P=\frac{Q_{\mathrm{s}}}{\Delta v} \int_{T_{1, \text { start }}}^{T_{1, \text { end }}} \mathrm{d} P
$$

We obtain an expression for the pressure variation for the considered solidification increment

$\Delta P=\frac{Q_{\mathrm{s}}}{\Delta v} \ln \frac{T_{1, \text { end }}}{T_{1, \text { start }}}$

The left-hand side of Eq. (5) expressed as $\Delta P=P_{2}-$ $P_{1}$ is the unknown pressure variation $(\mathrm{Pa})$, while the terms on the right-hand side of the Eq. (5) can be calculated based on temperature and volume change measurements.

The released latent heat $Q_{\mathrm{s}}$ within a delimited solidification increment is calculated from the following equation:

$Q_{\mathrm{s}}=\frac{q_{\mathrm{s}} \Delta t}{\frac{M}{V}}$

where $q_{\mathrm{s}}\left(\mathrm{W} \mathrm{m} \mathrm{m}^{-3}\right)$ is the volumetric heat release within the solidification increment, which is calculated using a Fourier thermal analysis (FTA). The parameter $M(\mathrm{~kg})$ is the measured mass of the sample, $V\left(\mathrm{~m}^{3}\right)$ is the current sample volume calculated from the dilatation measurement, and $\Delta t(\mathrm{~s})$ is the duration time of the studied solidification increment.

FTA is an iteration algorithm based on a numerical interpretation of the Fourier heat conduction equation with the scope to interpret the registered temperature differences within the phase transformation of a sample domain (e.g., solidification of cast iron in a spherical sample). Furthermore, it is possible to determine the released latent heat during the phase transformation. Beside the registered cooling rates, the following tabulated data were used as input for the FTA calculation: Heat capacity of liquid iron, $c_{\mathrm{P}}^{\text {liq }}=740 \mathrm{~J} \mathrm{~kg}^{-1} \mathrm{~K}^{-1}$; Density of the liquid iron, $\rho^{\text {liq }}=$ $7100 \mathrm{~kg} \mathrm{~m}^{-3}$; Heat capacity of austenite, $c_{\mathrm{P}}^{\mathrm{gr}}=$ $1950 \mathrm{~J} \mathrm{~kg}^{-1} \mathrm{~K}^{-1}$; Density of austenite, $\rho^{\text {aus }}=7400$ $\mathrm{kg} \mathrm{m}^{-3}$; Heat capacity of graphite, $c_{\mathrm{P}}^{\mathrm{gr}}=1950$ $\mathrm{J} \mathrm{kg}^{-1} \mathrm{~K}^{-1}$; Density of graphite, $\rho^{\mathrm{gr}}=2200 \mathrm{~kg} \mathrm{~m}^{-3}$. The heat capacity values were calculated by using ThermoCalc software [16]. Density values were used from the literature. The FTA algorithm was developed in the department of Material and Manufacturing, Jönköping University, and has previously been published in the present journal $[17,18]$. The specific volume change $\Delta v\left(\mathrm{~m}^{3} \mathrm{~kg}^{-1}\right)$ within a delimited solidification increment is calculated by using the following equation:

$\Delta v=\frac{\Delta V}{M}$

where $\Delta V\left(\mathrm{~m}^{3}\right)$ is the volume change of the sample within a solidification increment calculated from the measured sample volume change and the measured sample mass $M$. The temperature terms $T_{1, \text { start }}$ and $T_{1, \text { end }}$ in Eq. (5) are given in Kelvin units.

\section{Results and Discussions}

The cooling curves collected during the solidification experiment are presented as a function of the fraction of solidified material calculated by the FTA algorithm in Fig. 4.

$T_{1}$ is the cooling curve registered from the geometrical center of the spherical sample, and $T_{2}$ is the average of the temperatures measured at three different positions on the surface of the sample. Figure 4 includes also the calculated volume change, based on the measured surface displacement. The sample volume decreases from the start of the solidification until the total fraction of solid $f_{\mathrm{s}}$ reaches a value of 0.32 . In terms of solidification morphology, the columnar zone (casting skin) forms on the internal surface of the casting sample, when the solidification starts. Thereafter, it continues to grow and coarsen until the graphite precipitation starts in the columnar zone. The start of the graphite precipitation is also confirmed by a temperature minimum at $f_{\mathrm{s}}=0.32$ at the surface temperature $T_{2}$. The consequent volume increase continues until the internal domain (the equiaxed zone) reaches a temperature

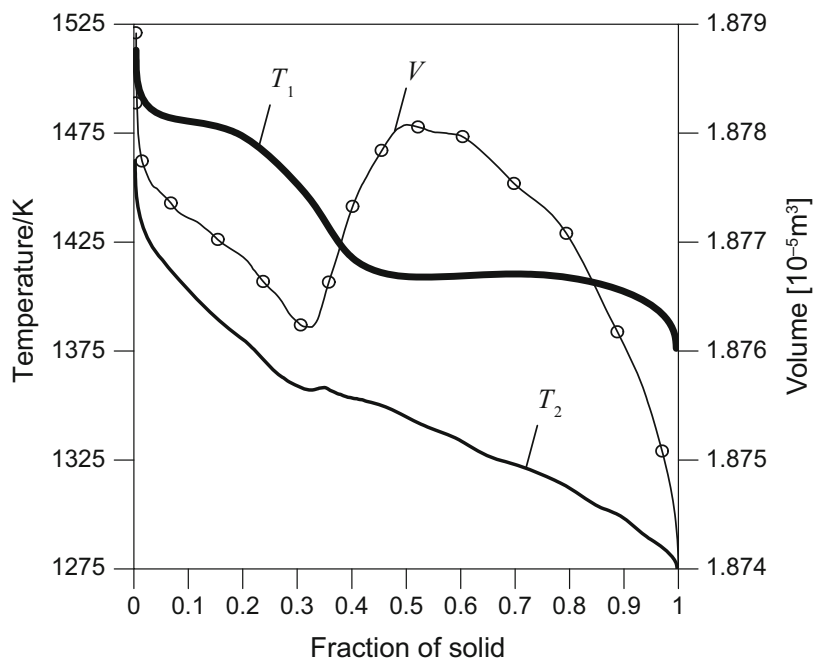

Fig. 4 Cooling curves and the calculated volume at different solid fractions in the melt 
minimum on the central cooling curve $T_{1}$ at $f_{\mathrm{s}}=0.52$. The volume starts to increase when the graphite formation starts, which is confirmed by the peak of the eutectic reaction on the $T_{2}$ curve. The minimum value on the $T_{1}$ curve corresponds to the beginning of recalescence, which is the beginning of a massive solidification with a significant release of latent heat. The decrease in volume is related to an insufficient graphite formation to compensate for the austenite shrinkage due to the temperature decrease. From this moment, the total volume of the sample will decrease toward the end of the solidification.

Heat transport from the spherical sample to the surrounding is equally distributed over the sample shell. Consequently, the columnar zone precipitation will create a container-like domain, which hinders a direct contact between the outer atmosphere and the bulk liquid. The equiaxed austenite grains precipitating inside the container consist of a mixture of a dendrite network and an intradendritic liquid, which transforms into a solid granular unit when the intradendritic liquid transforms to graphite and eutectic austenite. The extradendritic area will be the last solidifying area. The interaction between the intradendritic and extradendritic liquid during solidification cannot be interpreted from this measurement. For the sake of simplicity, the calculated pressure change based on Eq. 5. will be interpreted as the pressure change of the liquid phase in the extradendritic zone.

The calculated pressure variation is presented together with the measured temperature in the geometrical center in Fig. 5, with the calculated volume change in Fig. 6, and with the calculated released latent heat in Fig. 7. In all cases as a function of fraction solidified material.

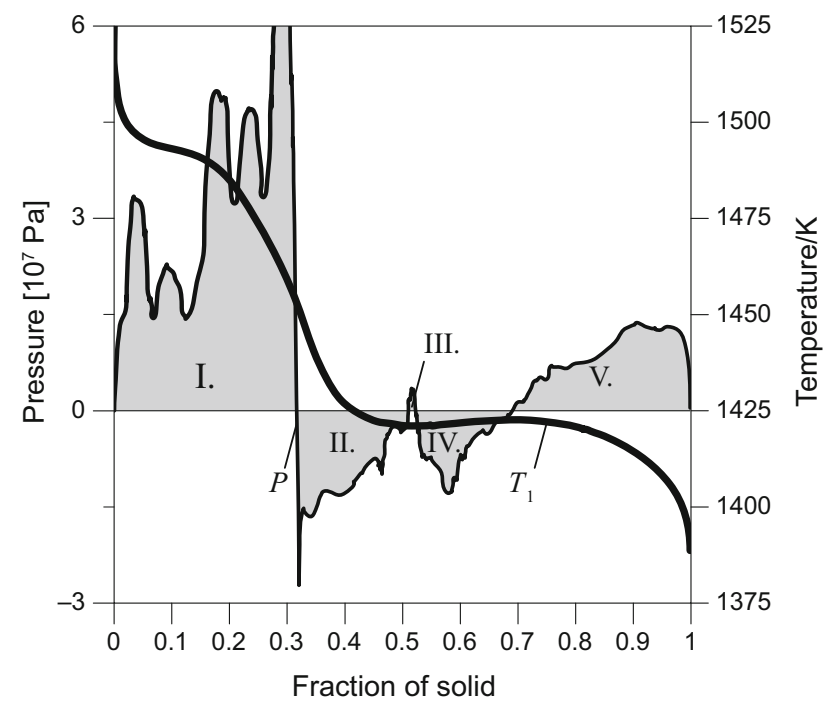

Fig. 5 Calculated pressure and measured temperature as a function of fraction solid

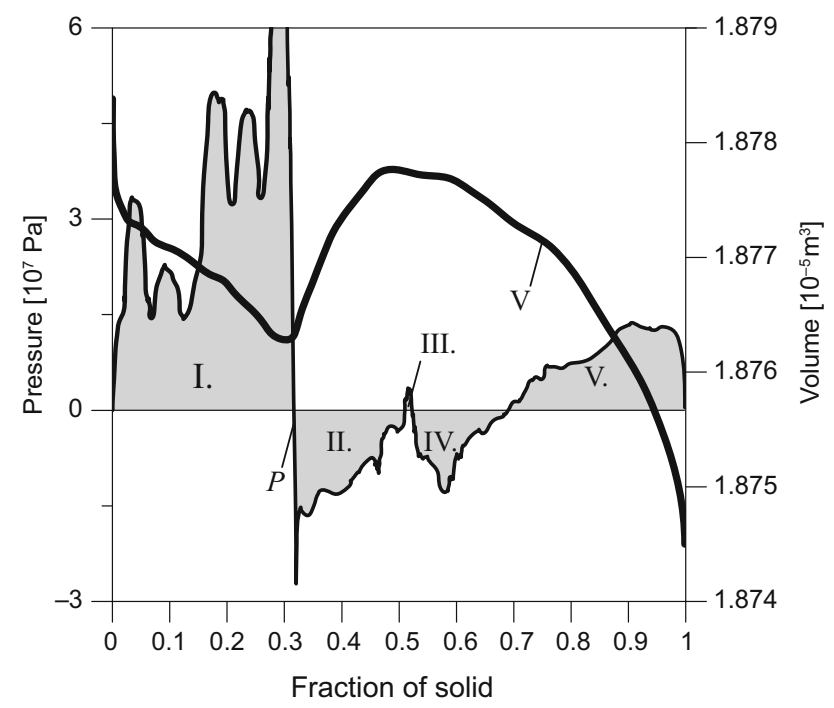

Fig. 6 Calculated pressure and calculated volume change as a function of fraction solid

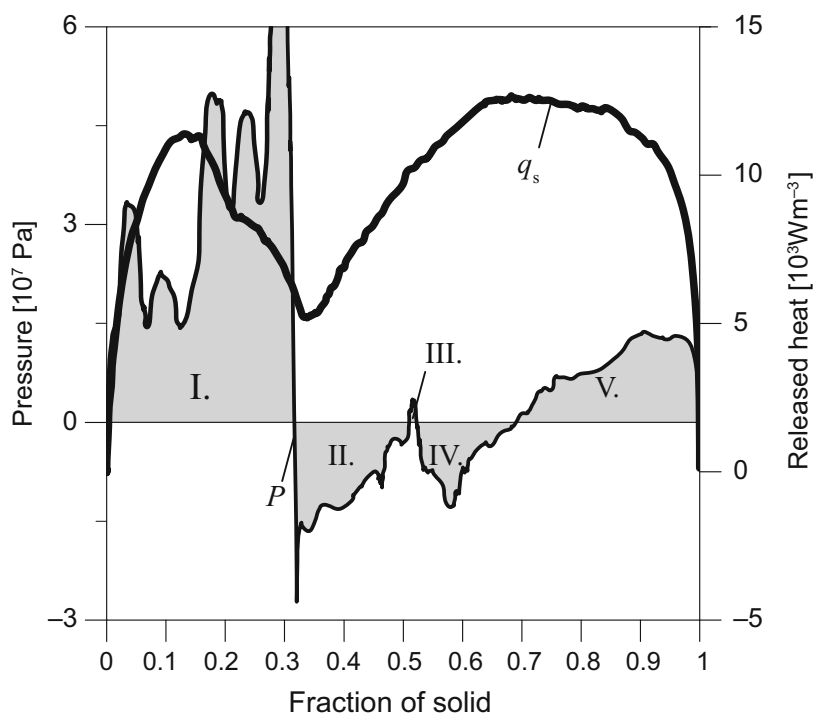

Fig. 7 Calculated pressure and calculated released latent heat as a function of fraction solid

The deviation from the atmospheric pressure $\Delta P=0$ starts as soon as the solidification starts and continues until the end of solidification. A continuous deviation is observed based on the performed calculations. Positive values on the $\mathrm{y}$-axis are interpreted as a compressive pressure, while negative values are considered to be an expansion pressure. The alteration between the compressive and expansion pressures is strictly related to the measured temperature (Fig. 5), the calculated volume change (Fig. 6) and released latent heat (Fig. 7) variation. The investigated hypoeutectic cast iron in the present paper seems to develop expansion pressures in two distinct intervals of the solidification. The first interval developing 
expansion pressure (indicated as II.) can be connected to the expansion of the columnar zone (casting shell), which causes a volume expansion lasting to the start of the eutectic reaction in the equiaxed zone. The second interval where an expansion pressure is developed (indicated as IV.) starts behind the eutectic minimum temperature of the equiaxed zone. Thereafter, it lasts until the maximum recalescence of the equiaxed zone is reached. The remaining intervals are characterized to have a compressive pressure (indicated as I, III and V).

The maximum expansion pressure in both intervals is $-1.5 \times 10^{7} \mathrm{~Pa}$. One of the few existing literature data by Campbell discusses an analytical model and calculates the hydrostatic tension of the solidifying liquid in different pure alloys [7]. Furthermore, it presents information related to a planar solidification front and different deformation characteristics of the solidifying crust. Campbell reports a dimension-dependent hydrostatic tension. For small calculation domains of trapped liquids $\left(10^{-6} \mathrm{~m}\right)$, the reported hydraulic tension data were in the range of $-10^{9}$ to $-10^{10} \mathrm{~Pa}$. The discrepancies between the present and literature data may be due to the differences of the alloy, the differences between the deformation characteristic of the solidifying crust and the used input data.

Several measurements of alloys with similar chemical compositions as the present investigated alloy were performed. Since the reproducibility of the instrument was not the scope of the present paper, the reproducibility will be reported in a future work. The accuracy of the implemented sensors in the measurements is described in the experimental chapter.

Integration of the heat release in the whole solidification interval within the FTA calculation gives the sum of the latent heat of solidification $L=254 \mathrm{~J} \mathrm{~kg}^{-1}$. It is worth to note that the calculated latent heat in the present work corresponds well to the calculated latent heat when using the ThermoCalc [16] software for the composition indicated in Table 1.

The present investigation confirms the various pressure states, tensile and compressive loads of the solidifying liquid in the extradendritic area at solidification of lamellar graphite iron. Consequently, the driving forces for the formation of SP and MEP defects are demonstrated to exist within the same solidification process. Further utilization of the present method is aimed to investigate the extremely sensitive solidification process of cast iron alloys with respect to parameters such as the composition, morphology and refining treatments.

\section{Conclusions}

The focus was the determination of the pressure in the extradendritic liquid area during solidification of lamellar graphite iron. A new method based on the interpretation of the Clausius-Clapeyron equation was introduced. The pressure variation of the liquid iron in the extradendritic area was determined with help of a novel experimental setup, where the temperature variation and the surface displacement are measured during solidification. A continuous deviation from the atmospheric pressure alternating between a compressive pressure and an expansion pressure was calculated. The alteration points between the positive and negative pressures can be connected to metallurgical key events that take place during solidification. A pre-eutectic expansion pressure is caused by an expansion of the casting skin. In total, three compressive and two expansion pressure intervals were identified for the investigated hypoeutectic alloy. The presence of expansion and compressive pressures in the extradendritic liquid indicates the existing driving forces at the SP and MEP defect formations during solidification of lamellar graphite iron. When comparing the predicted data to the existing literature data, the calculated pressure deviation is lower than the values based on analytical calculations.

Acknowledgements The present work was performed within the Casting Innovation Centre and financed by the Swedish Knowledge Foundation. Cooperating parties in the project are Jönköping University, Scania CV AB and Volvo Group Trucks Operations. The participating persons from these institutions/companies are acknowledged for their support throughout this study.

Open Access This article is distributed under the terms of the Creative Commons Attribution 4.0 International License (http://crea tivecommons.org/licenses/by/4.0/), which permits unrestricted use, distribution, and reproduction in any medium, provided you give appropriate credit to the original author(s) and the source, provide a link to the Creative Commons license, and indicate if changes were made.

\section{References}

1. Diószegi A, Svidró P, Elmquist L, Dugic I. Defect formation mechanisms in lamellar graphite iron related to the casting geometry. Int J Cast Met Res. 2016;29:279-85.

2. Lora R, Diószegi A. Dynamic coarsening of 3.3C-1.9Si gray cast iron. Metall Mater Trans A. 2012;43:5165-72.

3. Diószegi A, Liu KZ, Svensson IL. Inoculation of primary austenite in grey cast iron. Int J Cast Met Res. 2007;20:68-72.

4. Carlson GA. Dynamic tensile strength of mercury. J Appl Phys. 1975;46:4069-70.

5. Campbell J. Chapter 7 - Porosity. Complete cast handb. 2nd ed. Amsterdam: Elsevier; 2015. p. 395.

6. Campbell J. Hydrostatic tensions in solidifying alloys. Trans Metall Soc AIME. 1968;242:268-71.

7. Campbell J. Hydrostatic tensions in solidifying metarials. Trans Metall Soc AIME. 1968;242:264-8.

8. Campbell J. Shrinkage pressure in castings. Trans Metall Soc AIME. 1967;239:138-42.

9. Chisamera M, Riposan I, Stan S, Barstow M. Simultaneous cooling and contraction/expansion curve analysis during ductile iron solidification. Trans Am Foundrymens Soc. 2012;120:375-88. 
10. Alonso G, Stefanescu DM, Suarez R, Loizaga A, Zarrabeitia G. Kinetics of graphite expansion during eutectic solidification of cast iron. Int J Cast Met Res. 2014;27:87-100.

11. Mrvar P, Medved J, Križman A. Control of microstructure during the eutectoid transformation in the As-cast spheroidal graphite cast iron with "in situ" dilatation analysis and quenching experiments. Steel Res Int. 2006;77:361-9.

12. Mrvar P, Tribžan M, Medved J, Križman A. Study of the eutectoid transformation in the As-cast spheroidal graphite cast iron with "in situ" dilatation analysis-method for quality control. Mater Sci Forum. 2006;508:287-94.

13. Tadesse A, Fredriksson H. The effects of carbon on the solidification of nodular cast iron-its study with the help of linear variable differential transformer and microstructural analysis. Int J Cast Met Res. 2017;1-10.
14. Svidró P, Diószegi A. On problems of volume change measurements in lamellar cast iron. Int J Cast Met Res. 2013;27:26-37.

15. Stefanescu DM. Science and engineering of casting solidification. 3rd ed. New York: Springer; 2015.

16. Thermo-Calc. Database: TCFE7-Steels/ferrous alloys. Stockholm: Thermo-Calc AB; 2016.

17. Svidró JT, Diószegi A, Tóth J. The novel application of Fourier thermal analysis in foundry technologies. J Therm Anal Calorim. 2014;115:331-8.

18. Diószegi A, Diaconu V-L, Fourlakidis V. Prediction of volume fraction of primary austenite at solidification of lamellar graphite cast iron using thermal analyses. J Therm Anal Calorim. 2016;124:215-25. 